\title{
Stem cell based glioblastoma gene therapy
}

\author{
Minireview ${ }^{* *}$ \\ C. ALTANER*, V. ALTANEROVA \\ Cancer Research Institute SAS, Bratislava, Slovakia, \\ ${ }^{*}$ Correspondence: exonalt@savba.sk
}

Received February 10, 2012 / Accepted May 26, 2012

\begin{abstract}
There is no curative therapy for glioblastoma multiforme (GBM) thus far. Combined therapies including surgery, followed by concomitant irradiation and chemotherapy with the DNA alkylating agent temozolomide (TMZ), slightly improves patients' survival but the prognosis remains poor. The fatal nature of glioblastoma is caused by tumor-initiating glioblastoma cells. The tumor tropic ability of adult mesenchymal stem cells offers the attractive possibility to use these cells as a vehicle to deliver therapeutic agents to the site of the tumor. In preclinical studies using animal models, mesenchymal stem cells engineered to express suicide genes were shown to elicit a significant antitumor response against various tumors including glioblastoma. This review summarizes the current state of knowledge about stem cell directed glioblastoma therapy. Results obtained in a preclinical study using mesenchymal stem cells engineered to express cytosine deaminase provided evidence that stem cell based gene therapy might also attack glioblastoma stem cells and therefore be curative. In addition to stem cell directed prodrug gene therapies, other immunotherapeutic modalities using mesenchymal stem cells are discussed as well. Encouraging results of preclinical studies of stem cell based gene therapy for glioblastoma support the argument to begin clinical studies.
\end{abstract}

Key words: glioblastoma, glioblastoma stem cells, chemoresistance, radio-resistance, stem cell driven gene therapy, prodrug gene therapy, preclinical studies

Malignant astrocytic gliomas, including the most common subtype, glioblastoma multiforme (GBM), are the most frequent and lethal intracranial tumors. The median survival for patients diagnosed with a WHO grade III glioma (anaplastic astrocytoma, anaplastic oligoastrocytoma and anaplastic oligodendroglioma) and grade IV glioma (glioblastoma multiforme) is only 8 to 15 months [1]. The prognosis for recurrent malignant glioma with present therapies is poor; with a median survival of 3 to 9 months. Generally, glioblastoma is usually fatal within a year of diagnosis.

The current standard glioblastoma therapy includes surgery followed by concomitant radiation and chemotherapy with the DNA alkylating agent temozolomide (TMZ). This is at present the best chemoradiotherapy approach providing modest improvement of the overall survival for a subset of
TMZ-sensitive glioblastoma patients. The presence of O6methylguanine-DNA methyltransferase (MGMT) which repairs the most cytotoxic lesions generated by TMZ is one of the reasons for therapeutic failure in glioblastoma patients. Resistance to TMZ is also caused by the base excision repair enzyme alkylpurine-DNA-N-glycosylase (APNG), which repairs the cytotoxic lesions N3-methyladenine and N7-methylguanine [4]. Furthermore it was reported that in tissue culture experiments normal neural stem/progenitors and glioma stem-like cells have differential sensitivity to chemotherapy. The commonly-used chemotherapy drug TMZ affects normal stem cells more than tumor-related stem cells [5].

Despite the current combined therapy for glioblastoma that slightly improves survival for patients with newly-diagnosed

${ }^{*}$ Presented on the XX. Biological Days - Stem cells - from regenerative medicine to cancer, Pilsen, October 25-27, 2011 


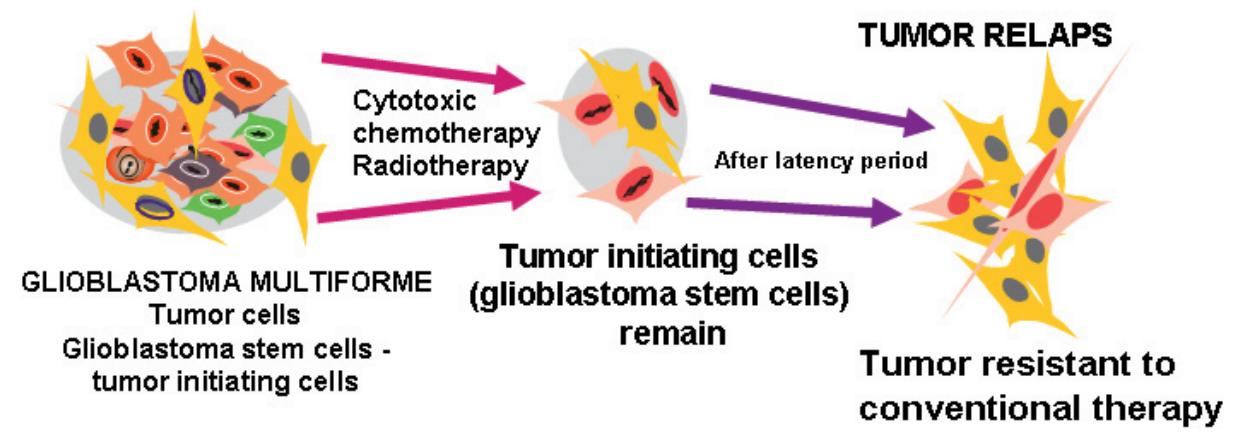

Figure 1. Selection of glioblastoma stem cells after radiotherapy and cytotoxic therapy. After short latent period relapsed resistant tumor progresses.

glioblastoma, the prognosis remains poor, with a median survival time of 12 to 15 months. It is believed that the reason for this poor outcome is the tumor's polyclonal composition - clones of dividing tumor cells and few tumor initiating cells. Radiotherapy and chemotherapy kill dividing cells, but slowly dividing cancer stem cells remain unaffected. The cytotoxic therapy selects for the more aggressive cancer stem cells. Consequently, there is frequent relapse following cytotoxic therapies, with tumors resistant to further conventional therapy (Figure 1).

GBM's biological properties such as resistance to chemotherapy and radiotherapy, its infiltrative nature, proliferative behavior, and progressive character, are caused by the presence of glioblastoma stem cells (GSCs). GSCs share many of the properties of normal stem cells, such as the ability to self renew, resistance to toxic compounds, asymmetric cell division, etc. [for a review see 2]. It has also been postulated that GSCs are more resistant to the hypoxic and acidotic tumor microenvironment [3].

There is so far no curative therapy for GBM. New therapeutic approaches which are able to attack both tumor cells and tumor initiating cells holds hope for curative treatment of aggressive tumors like glioblastoma. Previously, two prodrug gene therapy systems using virus for transgene transfer have been studied: cytosine deaminase /5-FC system and Herpes simplex virus thymidine kinase (HSVtk)/ganciclovir. The first clinical trials for the treatment of malignant glioma were conducted in the 1990s with Herpes simplex virus thymidine kinase in combination with ganciclovir [6]. The potential of these classic gene therapies for glioma treatment was augmented when the tumor tropic property of mesenchymal stem cells (MSC) was discovered. The tumor tropic property of MSCs is the basis for therapies using MSCs as a vehicle for delivery of the therapeutic agent to the site of neoplasm. The physiological role of mesenchymal stem cells is to repair damaged and used tissue in the organisms. MSCs possess the ability to migrate to the site of injury. The tumor, being a "wound that does not heal" [8], attracts MSCs. The MSCs home in the tumor and, together with other cells, form tumor stroma. MSCs from bone marrow or from adipose tissue have tumor migratory ability and have been shown to share some characteristics with pericytes $[9,10]$. This property might facilitate the migration of MSCs to highly vascularized glioblastomas. We recently reviewed the molecular mechanisms of MSCs' migration and homing to tumors [11].

Tumor targeting therapy, driven by mesenchymal (stromal) stem cells brought hope for a therapeutic modality, which would kill both tumor cells and glioblastoma stem cells. Aboody et al. [7] summarized the first experimental evidence that neural and mesenchymal stem cells can deliver therapeutic genes to elicit a significant antitumor response in animal models of intracranial glioma, medulloblastoma, melanoma brain metastasis, disseminated neuroblastoma and breast cancer lung metastasis. Most studies reported a reduction in tumor volume and an increased survival of tumor-bearing animals. Complete cures have also been achieved in mice bearing disseminated neuroblastoma tumors. Disease-free survival for more than one year in $90 \%$ of animals was observed.

Cytosine deaminase/5-FC system. Prodrug cancer gene therapy driven by MSCs might be one of several treatments with potential for curative therapy of brain tumors. It represents an attractive tool for activating the prodrug directly within the tumor mass, thus avoiding systemic toxicity. In addition, MSCs lack major histocompatibility complex MHC-II and show only minimal MHC-I expression [12-14]. Thanks to their immunosuppressive properties, allogeneic MSCs can substitute for autologous stem cells. Mesenchymal stem cells possess many attributes that support their use as a tumor specific therapeutic vehicle in clinical practice. They are relatively easy to isolate by adherence to plastic and have enormous expansion potential in tissue culture. Human MSCs reside in many tissues in small numbers but most isolation is performed from the bone marrow (BM-MSCs) or from adipose tissue (AT-MSCs). BM-MSCs and AT-MSCs are very similar in their ability to migrate toward sites of tissue injury as well as in tumor tropic ability. Previously, we have shown that human adipose tissue-derived mesenchymal stem cells can be transduced with yeast fusion cytosine deaminase: uracil phosphoribosyltransferase, the gene which 
can convert non-toxic 5-fluorocytosine (5-FC) to effective cytotoxic compound 5-fluorouracil (5-FU). Such cells designated CDy-AT-MSCs are called therapeutic stem cells. In several papers, we proved the ability of AT-MSCs engineered to express cytosine deaminase to inhibit significantly growth of human colon cancer xenografts [15], melanoma and other cancers [16]. In a pilot preclinical study, we observed that co-injections of human bone metastatic prostate cancer cells along with therapeutic stem cells into nude mice treated with 5-FC induced a complete tumor regression in a dosedependent manner. Furthermore, we demonstrated that the therapeutic stem cells were effective in significantly inhibiting prostate tumor growth after intravenous administration, a key requisite for any clinical application [17]. We and others [7] are encouraged by the results of stem cell driven enzyme prodrug therapy experiments to treat glioblastoma multiforme, a tumor with fatal prognosis. Aboody et al.[7] demonstrated that neural stem cells (NSCs) administered intracranially possess extensive tropism for experimental glioma. Immortalized NSCs engineered to express bacterial cytosine deaminase have been exploited as a tumor-targeting strategy for glioma gene therapy. Preclinical studies accomplished in Abbody's groups lead to, the first clinical study entitled "A Pilot Feasibility Study of Oral 5-Fluorocytosine and Genetically-Modified Neural Stem Cells Expressing E. Coli Cytosine Deaminase for Treatment of Recurrent High Grade Gliomas" ( http://www.clinicaltrials.gov/ct2/show/ NCT01172964?term\%C4\%BDstem\%20cell'\%20AND\%20c ancer\%20\%20AND\%20gene\&rank\%C4\%BD6).

Our experiments took the advantage of the fact that human AT-MSCs are not immunogenic in treatment of rat glioblastoma growing intracebroventricularly. The cell population of C6 rat glioblastoma has been shown to be composed primarily of cancer stem cells [18-20]. Therapeutic experiments were designed to simulate conditions of future clinical application for high-grade glioblastoma therapy by direct injections of therapeutic stem cells into the tumor. Results revealed that genetically modified therapeutic stem cells still have the tumor tropism when injected to a distant intracranial site and effectively inhibit glioblastoma growth after 5 -fluorocytosine (5-FC) therapy. Intratumoral administration of therapeutic stem cells improved the survival in a therapeutic stem cell dose-dependent manner. Furthermore, the repeated administration of therapeutic cells and continuous intracerebroventricular delivery of 5-FC led to an increased number of animals being completely cured. Intracerebral injection of therapeutic stem cells and treatment with 5-FC did not show any detectable adverse effects [21].

Herpes simplex virus thymidine kinase/ganciclovir system. The system is based on the ability of Herpes simplex virus thymidine kinase (HSV-tk) efficiently phosphorylates prodrug ganciclovir to its monophosphate, which is further phospohorylated by cellular enzymes to GCV-triphosphate (GCV-TP). Unlike in the cytosine deaminase/5-FC system where 5 -FU being small molecule easily passively diffuses to cells, cytotoxic GCVtriphosphate is a large molecule. Major mechanism responsible for the GCV-TP transfer into neighboring cells is gap junctions' formation between the cells in close contact.

It has been demonstrated that AT-MSCs expressing HSVtk are able to exert a cytotoxic effect on human glioblastoma cells in vitro and that formation of gap junctions is crucial for induction of the bystander cytotoxic effect on tumor cells [22]. A preclinical study confirming the feasibility of this approach on glioma in vivo has been demonstrated using neural stem cells (NSCs) as a HSVtk-delivery vehicle [23]. However, MSCs transduced with HSVtk is a more feasible and practical approach for clinical application than the method using NSCs [24]. There are several recent reports demonstrating the efficacy of BM-MSCs expressing HSVtk for tumor therapy [25]. Overexpression of connexin 43 together with HSVtk was shown to enhance the bystander effect of ganciclovir suicide gene therapy by restoration of gap junctions [26]. Mori et al. confirmed the tumor retarding effect of HSVtk-expressing BM-MSCs on rats bearing intracranial murine gliomas [27]. BM-MSCs transduced with a baculoviral vector harboring HSVtk were recruited to tumors after systemic injection. The strong expression of transgenes in MSCs transduced by baculovirus vectors might be an advantage over retrovirus vectors typically used in this system [28].

Stem cell driven rabbit carboxylesterase/CPT-11 system. Genetically modified human AT-MSCs expressing rabbit carboxylesterase enzyme, which can efficiently convert the prodrug CPT-11 (irinotecan-7-ethyl-10-[4-(1-piperidino)1-piperidino]carbonyloxycamptothecin) into the active drug SN-38 (7-ethyl-10-hydroxycamptothecin), were tested against brainstem glioma tumor which does not have response to any effective therapy. The transduced AT-MSCs revealed some therapeutic potential against the rat diffuse pontine glioma model [29].

Stem cells driven therapeutic cytokines and proapotopic genes. Mesenchymal stem cells can be genetically engineered to express therapeutic cytokines interleukin-18, interleukin 2 [30 - 32], and interferon gamma [33] to augment the immune response to the tumor. In vivo efficacy animal experiments showed that intratumoral injection of umbilical cord blood derived MSCs engineered to express interleukin-12 (UCB-MSC-IL12M) significantly inhibited tumor growth and prolonged the survival of glioma-bearing mice compared with control mice. Interestingly, after treatment tumor-free mice were resistant to tumor re-challenge, which was closely associated with tumor-specific long-term T-cell immunity [34].

Human bone marrow-derived mesenchymal stromal cells expressing proapoptotic agent S-TRAIL were shown to be a cellular delivery vehicle for human glioma therapy [35] or metastatic pancreatic carcinoma cells [36]. Recently, Kauer et al [37] simulating the clinical scenario of GBM treatment have shown that after surgical debulking of human GBM tumors in mice, when stem cells encapsulated in biodegrad- 
able, synthetic extracellular matrix (sECM) were inoculated in the resection cavity, tumor regrowth was delayed. In addition, therapeutic stem cells engineered to express secretable apoptosis inducing ligand S-TRAIL encapsulated in sECM eradicated residual tumor cells, which resulted in increased survival.

\section{Conclusions}

Mesenchymal stem cells, engineered to express suicide genes, and preferentially migrating and targeted to tumor cells, are the most attractive candidates for stem cell driven cancer therapy for clinical applications. Therapeutic stem cells must be selected for 100 percent transgene transduced cells to avoid potential tumor growth support from naïve MSCs. Their non- immunogenic nature and self-elimination of therapeutic stem cells due to suicide gene presence is an advantage. Despite very promising results from experimental studies of glioblastoma treatment with mesenchymal stem cells transduced with yeast fusion cytosine deaminase: uracil phosphoribosyltransferase [21], it is not realistic to expect that patients with relapsed tumors after standard therapies represent good candidates for successful curative glioblastoma therapy. However, treatment with therapeutic stem cells could prolong the period of remission. Considering the complexity of glioblastoma growth and consequences of standard toxic therapies (radiotherapy and concomitant chemotherapy) for relapsed patient, the stem cell driven therapy might be curative when will be used in patients with neurosurgical tumor extirpation. It is likely that the combination of stem cell directed prodrug gene therapy with immnostimulation via inoculation of MSCs genetically modified with potent cytokines or proapototic gene products is the way to augment therapeutic MSCs effect. The efficacy and safety of such combinations should be tested. It would be interesting to discover whether encapsulated mesenchymal stem cells transfected with tumor antigens could serve as a tumor vaccine in similar way to dendritic cell vaccines.

Acknowledgements: We wish to thank to the Slovak League against Cancer, SPP Foundation and FIDURA Capital Consult GmbH, Munich, Germany for support.

\section{References}

[1] LOUIS DN, OHGAKI H, WIESTLER OD, WIESTLER OD, CAVENEE WK, et al. The 2007 WHO classification of tumours of the central nervous system. Acta Neuropathol 2007; 114: 97-109. http: //dx.doi.org/10.1007/s00401-007-0243-4

[2] ALTANER C. Glioblastoma and stem cells Review. Neoplasma 2008; 55: 369-374.

[3] ISCHENKO I, SEELIGER H, SCHAFFER M, JAUCH KW, BRUNS CJ. Cancer stem cells: How can we target them? Curr Med Chem 2008; 15: 3171-3184. http: //dx.doi.org/10.2174/ $\underline{092986708786848541}$
[4] AGNIHOTRI S, GAJADHAR AS, TERNAMIAN C, GORLIA T, DIEFES KL et al. Alkylpurine-DNA-N-glycosylase confers resistance to temozolomide in xenograft models of glioblastoma multiforme and is associated with poor survival in patients. J Clin Invest. 2011 Dec 12. pii: 59334. doi: 10.1172/ JCI59334.

[5] CHAMBERLAIN MC, BOTA DA, LINSKEY ME, SCHWARTZ PH. Neural stem/progenitors and glioma stem-like cells have differential sensitivity to chemotherapy. Neurology. 2011 Nov 29;77(22): e135-6. http: //dx.doi.org/10.1212/ WNL.0b013e318239ba7c

[6] PULKKANEN K. J., YLA-HERTTUALA S. Gene therapy for malignant glioma: current clinical status. Mol. Ther. 2005; 12: 585-598. http: //dx.doi.org/10.1016/j.ymthe.2005.07.357

[7] ABOODY KS, NAJBAUER J DANKS M K. Stem and progenitor cell-mediated tumor selective gene therapy Cell-mediated anticancer therapy. Gene Therapy 2008; 15: 739-752.

[8] DVORAK HF. Tumors: wound that do not heal. Similarities between tumor stroma generation and wound healing. N. Engl. J. Med. 1986; 315: 1650-1659.

[9] BEXELL D, SCHEDING S, BENGZON J. Toward brain tumor gene therapy using multipotent mesenchymal stromal cells vectors. Mol. Ther. 2010; 18: 1067-1075. http: //dx.doi. org $/ 10.1038 / \mathrm{mt} .2010 .58$

[10] BEXELL D, GUNNARSSON S, TORMIN A, DARABI A, GISSELSSON D, et al. Bone marrow multipotent mesenchymal stroma cells act as pericyte like migratory vehicles in experimental gliomas. Mol Ther 2009; 17: 183-190. http: //dx.doi. org/10.1038/mt.2008.229

[11] CIHOVA M, Altanerova V, ALTANer C. Stem Cell Based Cancer Gene Therapy. Mol. Pharmaceutics 2011; 8: 1480-1487. http: //dx.doi.org/10.1021/mp200151a

[12] LE BLANC K. Immunomodulatory effects of fetal and adult mesenchymal stem cells. Cytotherapy 2003; 5: 485-489. http: //dx.doi.org/10.1080/14653240310003611

[13] KOPPUlA P. R., CHELLURI L. K., POLISETTI N., VEMUGANTI G. K. Histocompatibility testing of cultivated human bone marrow stromal cells-a promising step towards pre-clinical screening for allogeneic stem cell therapy. Cell. Immunol. 2009; 259: 61-65. http: //dx.doi.org/10.1016/ j.cellimm.2009.05.014

[14] GRIFFIN MD, RITTER T, MAHON BP. Immunological aspects of allogeneic mesenchymal stem cell therapies. Hum. Gene Ther. 2010; 21: 1641-1655. http://dx.doi.org/10.1089/ hum.2010.156

[15] KUCEROVA L, ALTANEROVA, V, MATUSKOVA M, TYCIAKOVA S, ALTANER C. Adipose tissue-derived human mesenchymal stem cells mediated prodrug cancer gene therapy. Cancer Res. 2007; 67: 6304-6313. http: //dx.doi. org/10.1158/0008-5472.CAN-06-4024

[16] KUCEROVA L, MATUSKOVA M, PASTORAKOVA A. TYCIAKOVA S, JAKUBIKOVA J. et al. Cytosine deaminase expressing human mesenchymal stem cells mediated tumour regression in melanoma bearing mice. J. Gene Med. 2008; 10: 1071-1082. http: //dx.doi.org/10.1002/jgm.1239

[17] CAVARRETTA IT, ALTANEROVA V, MATUSKOVA M, KUCEROVA L, CULIG Z.et al Adipose tissue derived mes- 
enchymal stem cells expressing prodrug-converting enzyme inhibit human prostate tumor growth. Mol. Ther. 2010; 18: 223-231. http: //dx.doi.org/10.1038/mt.2009.237

[18] KONDO T, SETOGUCHI T, TAGA T. Persistence of a small subpopulation of cancer stemlike cells in the C6 glioma cell line. Proc Natl Acad Sci USA 2004; 101: 781-786. http: //dx.doi.org/10.1073/pnas.0307618100

[19] ZHENG X, SHEN G, YANG X, LIU W. Most C6 cells are cancer stem cells: evidence from clonal and population analyses. Cancer Res 2007; 67: 3691-3697. http: //dx.doi. org/10.1158/0008-5472.CAN-06-3912

[20] ZHOU XD, WANG XY, QU FJ, ZHONG YH, LU XD. et al. Detection of cancer stem cells from the C6 glioma cell line. J Int Med Res 2009; 37: 503-510.

[21] ALTANEROVA V, CIHOVA M, BABIC M, RYCHLY B, ONDICOVA K. et al. Human adipose tissue-derived mesenchymal stem cells expressing yeast cytosinedeaminase: : uracilphosphoribosyltransferase inhibit intracerebral rat glioblastoma, Int J Cancer. 2012;130: 2455-2463. http: // dx.doi.org/10.1002/ijc. 26278

[22] MATUSKOVA M, HLUBINOVA K, PASTORAKOVA A, HUNAKOVA L, ALTANEROVA V. et al. HSV-tk expressing mesenchymal stem cellsexert bystander effect on human glioblastoma cells. Cancer Lett. 2010; 290: 58-67. http: //dx.doi.org/10.1016/j.canlet.2009.08.028

[23] LI S, GAO Y, TOKUYAMA T, YAMAMOTO J, YOKOTA $\mathrm{N}$. et al. Genetically engineered neural stem cells migrate and suppress glioma cell growth at distant intracranial sites. Cancer Lett 2007; 251: 220-227. http: //dx.doi.org/10.1016/ j.canlet.2006.11.024

[24] AMANO S, LI S, GU C, GAO Y, KOIZUMI S. et al. Use of genetically engineered bone marrow- derived mesenchymal stem cells for glioma gene therapy. Int. J. Oncol. 2009; 35: $1265-1270$

[25] SONG C, XIANG J, TANG J, HIRST DG ZHOU J et al. Thymidine kinase gene modified bone marrow mesenchymal stem cells as vehicles for antitumor therapy. Hum. Gene Ther 2011; 22: 439-449. http: //dx.doi.org/10.1089/ hum.2010.116

[26] HUANG Q, LIU XZ, KANG C S, WANG GX. ZHONG Y et al. The anti-glioma effect of suicide gene therapy using BMSC expressing HSV/TK combined with overexpression of Cx43 in glioma cells. Cancer Gene Ther. 2010; 17: 192-202. http: //dx.doi.org/10.1038/cgt.2009.64

[27] MORI K, IWATA J, MIYAZAKI M, OSADA H, TANGE $\mathrm{Y}$ et al. Bystander killing effect of thymidine kinase genetransduced bone marrow stromal cells with ganciclovir on malignant glioma cells. Neurol. Med.-Chir. (Tokyo) 2010; 50: 545-553. http: //dx.doi.org/10.2176/nmc.50.545
[28] BAK XY, YANG J, WANG S. Baculovirus-transduced bone marrow mesenchymal stem cells for systemic cancer therapy. Cancer Gene Ther. 2010; 17: 721-729. http: //dx.doi. org/10.1038/cgt.2010.32

[29] CHOI SA, LEE JL, WANG KC, PHI JH, SONG SH et al. Human adipose tissue-derived mesenchymal stem cells: Characteristics and therapeutic potential as cellular vehicles for prodrug gene therapy against brainstem gliomas. Eur. J. Cancer 2012; 48: 129-137. http: //dx.doi.org/10.1016/ j.ejca.2011.04.033

[30] XU G, JIANG XD, XU Y, ZHANG J, HUANG FH. et al. Adenoviral-mediated interleukin-18 expression in mesenchymal stem cells effectively suppresses the growth of glioma in rats. Cell Biol. Int. 2009; 33: 466-474. http: //dx.doi.org/10.1016/ j.cellbi.2008.07.023

[31] STAGG J, LEJEUNE L, PAQUIN A, GALIPEAU J. Marrow stromal cells for interleukin-2 delivery in cancer immunotherapy. Hum. Gene Ther. 2004; 75: 597-608. http: //dx.doi. org/10.1089/104303404323142042

[32] EHTESHAM M, KABOS P, NEUMAN T, BLACK KL, YU JS. The use of interleukin-12-secreting neural stem cells for the treatment of intracranial glioma. Cancer Res. 2002; 62: 5657-5663.

[33] GUNNARSSON S, BEXELL D, SVENSSON A, SIESJO P, DARABI A. et al. Intratumoral IL-7 delivery by mesenchymal stromal cells potentiates IFN- $\gamma$-transduced tumor cell immunotherapy of experimental glioma. J. Neuroimmunol. 2010; 218: 140-144. http: //dx.doi.org/ 10.1016/j.jneuroim.2009.10.017

[34] RYU CH, PARK SH, PARK SA, KIM SM. LIM JY. et al. Gene Therapy of intracranial glioma using interleukin 12-secreting umbilical cord blood derived mesenchymal stem cells. Hum. Gene Ther. 2011; 22: 733-743. http: //dx.doi.org/10.1089/ hum.2010.187

[35] MENON LG, KELLY K, YANG HW, KIM SK, BLACK PM. et al. Human bone marrow-derived mesenchymal stromal cells expressing S-TRAIL as a cellular delivery vehicle for human glioma therapy. Stem Cells. 2009; 27: 2320-2330. http: //dx.doi.org/10.1002/stem.136

[36] MOHR A, ALBARENQUE SM, DEEDIGAN LYU R, REIDY M. et al. Targeting of XIAP Combined with Systemic Mesenchymal Stem Cell-Mediated Delivery of sTRAIL Ligand Inhibits Metastatic Growth of Pancreatic Carcinoma Cells. Stem Cells 2010; 28: 2109-2120. http://dx.doi.org/10.1002/ stem.533

[37] KAUER TM, FIGUEIREDO J, HINGTGEN S, SHAH K. Encapsulated therapeutic stem cells implanted in the tumor resection cavity induce cell death in gliomas. Nat Neurosci. 2011; 15: 197-264. http: //dx.doi.org/10.1038/nn.3019 